\title{
An Industrial Design-Oriented Engineering Economics Course*
}

\author{
Haytham Elmiligi and Scott Iverson \\ Faculty of Engineering, University of Victoria \\ Emails:\{Haytham, siverson\}@engr.uvic.ca
}

\begin{abstract}
This paper presents techniques and methods to improve engineering students' design skills through a project- based course. We developed a well-defined project to engage second year students in an authentic industrial design flow. This flow starts by studying the feasibility of a target project and progresses to the selection of the best alternative using various financial analyses. It then evaluates the project's potential success rate using pre-defined evaluation criteria. This project is implemented through the concurrent application of the textbook's theoretical concepts of engineering economics. By applying the project, we fill the gap between academic theoretical concepts and the industrial real-life design and creation of products. Finally, we prepared a professional document that explains the specifications, requirements, and guidelines of the project. It also helps students in choosing the proper topic of their project, in exploring different project alternatives, and in preparing appropriate project documentation.
\end{abstract}

\section{Introduction}

Engineering economy is the heart of making critical milestone decisions for any project [1]. It is important to give students the opportunity to gain a financialbased design experience when teaching an undergraduate engineering economy course. However, there are many questions concerning how to best teach the course so that the students are engaged and retain the methodology for use in $3^{\text {rd }}$ and $4^{\text {th }}$ year design courses. Even in a co-operative curriculum where students will have some practical work experience, the work term is often specialised and does not involve the principles of finance and economics. Furthermore, the students often do not gain a familiarity with industrial design requirements.

\footnotetext{
* This work was supported by the Design Engineering Office at the University of Victoria through a Curriculum Development Grant.
}

These issues are perceived as a problem for students that otherwise have an excellent academic record [2]. Applying the principles and concepts of the class into factual design projects can narrow this gap.

To better integrate the learning experience of the course, a concurrent project is developed to incorporate the techniques being taught in the class into one entrepreneurial initiative. This increases the student's exposure to comprehensive, real world applications by developing one initiative and observing those that the other teams create. Supported by a Curriculum Development Grant (CDG) funded by the Design Engineering Office at the University of Victoria, the authors developed the specifications, project design guidelines, and evaluation methodologies that use and reinforce the concepts that are currently being taught in the course. By following the project guidelines, students will expand the scope of their intellectual understanding by including the big picture elements in their analysis along with the concomitant variables associated with them. A case study is developed as an example to show students, step by step, how to 1) choose their project properly, 2) study and analyze the feasibility of their business, and 3) evaluate its potential for success.

Section 2 of this paper gives an overview of some related teaching techniques at other universities. Section 3 explains the proposed project specifications and requirements. To illustrate the concept, a case study is discussed in Section 4. Section 5 shows the anticipated impact on the design content of the curriculum. Finally we draw the conclusions and present new ideas for possible extensions of this work in Section 6.

\section{Related Work}

An engineering economics course is available in almost all universities in North America for students enrolled in engineering programs such as Electrical, 
Mechanical [3], Chemical [4], and Civil Engineering [5]. The course objectives are normally focused on introducing the principles of engineering economics, teaching students how to study and analyze the feasibility of a business model, and developing the required skills in economic analysis to make optimum economic and financial decisions [5]. Teaching the same course syllabus to students coming from different departments posses many challenges in the examples and case studies being taught during the course. Moreover, the course assessment differs from one university to another. Table 1 shows a comparison between different engineering economic courses offered with respect to course components and grading scheme.

Table 1: A comparison between different Engineering Economic courses offered with respect to the course components and grading scheme.

\begin{tabular}{|c|c|c|c|c|}
\hline Course & CHE249F & ECOR3800 B & ENGG3240 & ENGG 310 \\
\hline University & Toronto[4] & Carleton[5] & Guelph[6] & Alberta[7] \\
\hline Class attendance & $5 \%$ & $\mathrm{X}$ & $\mathrm{X}$ & $\mathrm{X}$ \\
\hline Exam/Quizzes & $90 \%$ & $80 \%$ & $60 \%$ & $80 \%$ \\
\hline Homework & $5 \%$ & $20 \%$ & $30 \%$ & $20 \%$ \\
\hline Reports/Journals & $5 \%$ (Bonus) & $\mathrm{X}$ & $10 \%$ & $\mathrm{X}$ \\
\hline Presentation(s) & $\mathrm{X}$ & $\mathrm{X}$ & $\mathrm{X}$ & $\mathrm{X}$ \\
\hline Project & $\mathrm{X}$ & $\mathrm{X}$ & $\mathrm{X}$ & $\mathrm{X}$ \\
\hline
\end{tabular}

We explored different engineering economic courses which are being taught at various universities in Canada, USA, and Europe, and compared them with respect to the course objectives, topics covered, course assessment measures, project specifications, and evaluation schemes. Based on this study, we developed detailed project requirements and specifications that incorporate the theoretical concepts and financial analysis techniques that are currently being taught in the class into one entrepreneurial initiative. Taking into consideration that this course is being taught to both electrical and mechanical engineering students at the University of Victoria, a case study is developed to guide students in the preparation of a professional project study and report.

\section{Proposed Project Guidelines}

In this section, we present the specification and requirements that have been developed for engineering economics (ENGR 280) at the University of Victoria. We first start with the guidelines to select an appropriate topic. Then, we explain the project specifications followed by basic definitions for clarification adopted from [1].

\subsection{Topic Selection}

We ask students to think about it as if they are starting a new business. From this point, we ask them to think back to their own work experiences, hobbies and interests. At the same time, try to research the market conditions and trends and think about services that are needed on-campus or in their neighbourhood. Think about what needs exist in the marketplace that haven't been filled. In fact, many small businesses are founded on the idea of creating a solution to a problem that didn't have an existing solution. Finally, we ask them to make sure that their idea can fit with the project requirements and specifications.

We believe that it is important to let students choose their own topic for the project rather than forcing them to work on a specific topic which might not be of interest to them. However, the selected topic must satisfy some requirements and specifications, which are explained in the following subsection, to make sure that 1) it achieves the project component objectives and also 2) the project work load is appropriate for the course and balanced for all teams.

\subsection{Project Specifications and Requirements}

For each project, students must study and analyze the feasibility of their business and evaluate its success through the following 10 steps:

1- Study mutually exclusive and/or independent options within their project and define various services and revenue alternatives.

In mentoring the teams, we make certain that the options that they delineate are mutually exclusive and that, in the process of choosing one, all other alternatives are excluded [1].

\section{2- Draw an initial cash flow diagram for each} project.

We make certain that the chart adequately summarizes the timing and magnitude of a sufficient number of cash flows as they occur over time.

3- Select the best alternative using:

a- Present worth analysis.

b- Future worth analysis.

c- Annual worth analysis. 


\section{d- Capitalized cost calculations. \\ e- Payback period calculations.}

We ask that the teams comment on the analysis and explain which method gives the most useable and easy to interpret results, and why.

4- Use different metrics to evaluate the best alternative in their project. Explain the significant impact of time and interest rate on the value and amount of money.

The students are asked to use the concept of making three estimates for each parameter (a pessimistic, a most likely, and an optimistic estimate) depending on the nature of the parameters. For instance, the pessimistic estimate may be the lowest value (salvage value as an example) or the largest value (such as asset first cost).

5- Construct at least 3-stage decision tree and use it to evaluate alternatives in their project. Explain by calculations how to trace the best decision path back through the tree.

Their decision trees should be structured to depict a relevant series of decisions required, and to explain how the outcome from one stage is important to the next stage of decision-making. The teams are also encouraged to expand the size of the tree and record how this process has helped them look more deeply at the overall project design.

6- Improve their analysis using the concept of utility theory.

Utility analysis provides an opportunity for coaching to help the teams define the relative satisfaction that clients are expected to derive from their product or service. This is a very important component to accurately evaluate the success rate of any project, especially for public projects supported by governments.

7- Use scenario analysis to develop and evaluate at least 2 expected scenarios for their project. Calculate the profit in each case and comment on the results. (Consider at least 7 variables in the analysis)

In most cases, the teams will build the scenario around the "best" and "worse" case outcomes. The "most likely" or expected outcome usually resides somewhere within the range skewed to one side or the other, not in the middle. In this step, we define the minimum number of variables to be considered in the analysis to avoid unbalanced analysis within different projects.

8- Study the impact of inflation on their project by determining the difference inflation makes between money now and money in the future through the following steps:

a- Calculate the present and future worth with an adjustment for inflation over 10 years time period. Draw a figure to explain the changes in the present and future worth for 3 different inflation rates.

b- Draw a 3-D curve to explain how the inflation rate affects the project's profit over 10 years time period. (Profit vs inflation vs time).

We make certain that the impacts of inflation are addressed throughout their analysis in a coherent fashion.

9- Use Linear Programming to optimize one of the main components in their project. (At least 2 constraints and 2 variables).

We help the teams conceptually formulate and use linear programming to maximize or minimize one of the major elements in their project. For instance, they can use linear programming to maximize the profit or minimize the price.

10- Apply straight line and declining balance depreciation models to their project. Explain by figures the changes in the book value versus time using the two models.

The students are asked to indicate the changes in decision-making and product design that this analysis will dictate.

Finally, we asked students to prepare a professional report that includes the following items:

1- A cover page which includes: project title, course number and name, group number, list of students' names and numbers, date of submission. 
2- One page abstract (doesn't exceed 500 words) explaining the main objectives, approaches, methodologies, and contributions.

3- Project flow chart illustrates the milestones in the project.

4- Complete analysis that covers all project requirements and specifications.

5- Individual statement from each student within the group explaining his or her responsibilities and contributions to the project.

As an important component of the project requirements, each team is asked to make a final 10 minute presentation to the class at the end of the term. This component helps students to learn how to prepare a business presentation and add a marketing flavour to the project.

\section{Case Study}

As a proof of concept, we apply the previous project requirements to study the feasibility of a promising idea for a new product. In this section, we provide an overview of the proposed project and highlight the design challenges that must be considered in the project financial study.

\subsection{Image to Voice (I2V) Project for the Blind}

The $\mathrm{I} 2 \mathrm{~V}$ product aims at translating images taken by a video camera into sounds. The system synthesizes the voice based on the input images and a database program connected with a GPS system as shown in Figure 1.

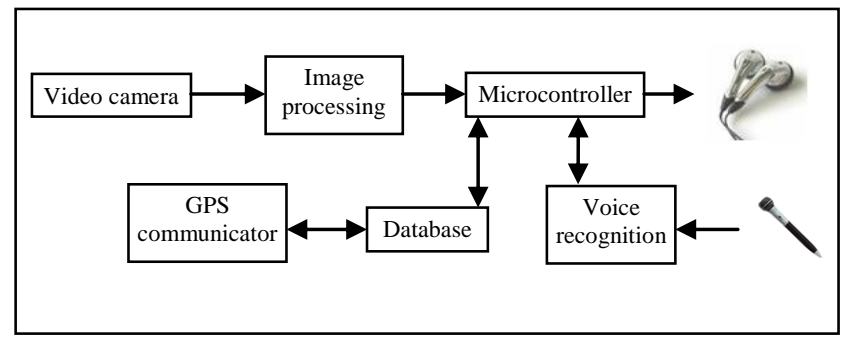

Figure 1: A block diagram for the I2V product

The product is planned to be packaged within stylish sunglasses. A hidden tiny video camera will be located at the middle of the frame and a microcomputer is implemented in a rear module behind the left ear position. The output voice comes out from the microcomputer to a sensitive earphone to deliver the translation of the images.

Using I2V, people with vision disabilities can go from any place to any other place by following the instructions and explanations given to them through the earphones. $\mathrm{I} 2 \mathrm{~V}$ is a learning device, so even if there are some new or temporary signs or building names that are not in the program, they can be easily entered by an assistant through a microphone which can be connected whenever it is needed.

\subsection{I2V Project Milestone Decisions}

Using concepts and techniques studied in the course, students are required to consider the following design decisions:

1- Decide whether to do the design by themselves or hire a third party company to do it, taking into consideration the cost, time and effort, quality and security of the design.

2- Decide whether to start the design from scratch or use pre-designed modules, taking into consideration cost and time-to-market factors.

3- Choose the technology that will be used in the hardware circuit design (FPGA/ASIC/Microprocessor/Microcontrolle rs), taking into consideration the cost, performance, design flexibility, and reconfigurability.

4- Decide whether to use professional tools or quick and simple tools for the PCB design, taking into consideration the cost, time, and tools features.

5- Decide which packaging should be used for the product, i.e. the design of the sunglasses and the materials used, etc.

6- Take a decision on the components' quantity that should be ordered for assembling the first mass production, taking into consideration the prices and new versions that might be available.

7- Decide what would be the optimum production plan based on present worth calculations (assume different scenarios).

8- Decide whether to do the advertising and marketing using newspapers, Internet, TV, or radio. 
9- Decide whether to do support the end user customer using call centres, interactive websites or by emails.

10- For the maintenance, whether to start a maintenance department or hire a third party company to do the maintenance.

In this case study, we highlight real-life project design challenges. By addressing these design issues, students will go through the real industrial design cycle. As the teams matriculate through the course material, they apply the concepts directly to the projects.

For example, if we want to plan for the production of the $\mathrm{I} 2 \mathrm{~V}$ product for the first two years, it is worth while to calculate the present worth value of the sales in this period. Assuming that we can sell the I2V for $\$ 160$, one scenario is to produce 50 pieces in the first month of the production. Then, as the production process becomes more stable, productivity will rise by $0.25 \%$ for the first two years. We assume that the interest rate is $1.5 \%$ per month, and that our marketing strategy is very efficient so that all devices are sold in the month in which they are produced (these assumptions can later be relaxed during a sensitivity analysis). We can use the present worth formula to find the present worth of sales [1]

$\mathrm{P}=\mathrm{A}(\mathrm{P} / \mathrm{A}, \mathrm{g}, \mathrm{i}, \mathrm{N})=\mathrm{A}\left(\left(\mathrm{P} / \mathrm{A}, \mathrm{i}^{\mathrm{o}}, \mathrm{N}\right) /(1+\mathrm{g})\right)$

Where $\mathrm{g}$ is the geometric gradient, $\mathrm{i}^{\mathrm{o}}$ is the growth adjusted interest rate, and $\mathrm{N}$ is the number of periods. In this example, the present worth of sales over the two-year period will be around $\$ 165,000$.

For the beginning of the term, we choose very simple examples so that the students can work on their projects starting from their first week of the class. Their analysis becomes more complex as the term continues and the students can immediately formulate their project design challenges into mathematical problems and apply the concepts currently being taught in the course. After each lecture, students learn new theoretical concepts and are asked to refine their analysis incorporating these concepts into the foundation that they have already built for their projects.

Homework problems still exist, but primarily for their practice value and as an indicator of variations on the implementation of techniques.

\section{Anticipated Impact on Design Content of Curriculum}

This project provides our students the opportunity to explore and work on a real application that evolves during the term. It also makes the course more design oriented and helps students better recognize the role they have as engineering decision makers.

Through adding the project component to the engineering economics course, the students better understand the importance of taking into account correct assessments of the costs and benefits of alternative design parameters. Teamwork will be promoted with real-world issues that are integrally tied to each student's progress and the overall learning objectives of the course.

The project also provides a systems engineering context for engineering economics by further addressing systems life cycles, stakeholder requirements, feasibility analysis, requirements analysis, synthesis and evaluation, systems specifications, technical performance measures, and appropriate design documentation.

\section{Conclusion and Future Work}

We performed a literature survey of case studies used in engineering economics courses for best practice guidelines and directions. Based on this survey, we developed and refined a new scenario-specific project that has a complexity suitable for the one-term engineering economics course. We basically developed a template for the teams to guide them through appropriate projects being careful to specify requirements sufficiently so no confusion or ambiguities existed but with enough flexibility built in for them to simulate a real world set of variables. As a proof of concept, a case study was presented to show how students can incorporate all the courses' concepts and financial analysis techniques into one entrepreneurial initiative.

We plan to extend this work to study the feasibility of applying work-based learning techniques in this project. That will include cooperation with local business representatives in the project selection, follow-up, and evaluation. 


\section{Acknowledgments}

The authors would like to give special thanks to the Design Engineering Office at the University of Victoria for funding this project. We especially wish to thank Mr. Jason J. Bazylak for his support and encouragement.

\section{References}

[1] Leland Blank, Anthony Tarquin, and Scott Iverson, Engineering Economics, Canadian Edition, McGrawHill Ryerson, Canada, 2008.

[2] Z Qi and James Cannan, Student/industry project in industrial-oriented undergraduate degree in electro-technology, In proceedings of 2006 annual conference of Using Cooperative Education and Work-integrated Learning to Develop Lifelong Learning Skills, pp. 107-115, 27-28 April, 2006, Queenstown, New Zealand.

[3] Engineering Economics Course, University of Victoria,[Online] http://web.uvic.ca/calendar2006/CDs /ENGR/280.html, 2006.

[4] Engineering Economics Course, University of Toronto,[Online] $h t t p: / / w w w . c m t e . u t o r o n t o . c a / p r o f i l e / s$ yllabus/04Sylla249f.pdf, 2004.

[5] Engineering Economics Course, Carleton University,[Online] $\underline{h t t p: / / w w w . c e e . c a r l e t o n . c a / o u t l i n e ~}$ s/PDFs/ECOR3800.pdf, 2006.

[6] Engineering Economics Course, University of Guelph,[Online]www.eos.uoguelph.ca/courseoutlinef0 7/ENGG3240.pdf, 2007.

[7] Engineering Economy Course, University of Alberta,[Online] http://www.mece.ualberta.ca/Courses lengg310/Zuo/07B-2008-Jan/310-syllabus-07B.htm, 2008. 